\title{
Improvements to an Explicit Algebraic Stress Model for Turbulent Jet Mixing Predictions
}

Nicholas J. Georgiadis and Dennis A. Yoder

Glenn Research Center, Cleveland, Ohio 


\section{NASA STI Program . . . in Profile}

Since its founding, NASA has been dedicated to the advancement of aeronautics and space science. The NASA Scientific and Technical Information (STI) Program plays a key part in helping NASA maintain this important role.

The NASA STI Program operates under the auspices of the Agency Chief Information Officer. It collects, organizes, provides for archiving, and disseminates NASA's STI. The NASA STI Program provides access to the NASA Technical Report Server-Registered (NTRS Reg) and NASA Technical Report ServerPublic (NTRS) thus providing one of the largest collections of aeronautical and space science STI in the world. Results are published in both non-NASA channels and by NASA in the NASA STI Report Series, which includes the following report types:

- TECHNICAL PUBLICATION. Reports of completed research or a major significant phase of research that present the results of NASA programs and include extensive data or theoretical analysis. Includes compilations of significant scientific and technical data and information deemed to be of continuing reference value. NASA counter-part of peer-reviewed formal professional papers, but has less stringent limitations on manuscript length and extent of graphic presentations.

- TECHNICAL MEMORANDUM. Scientific and technical findings that are preliminary or of specialized interest, e.g., "quick-release" reports, working papers, and bibliographies that contain minimal annotation. Does not contain extensive analysis.
- CONTRACTOR REPORT. Scientific and technical findings by NASA-sponsored contractors and grantees.

- CONFERENCE PUBLICATION. Collected papers from scientific and technical conferences, symposia, seminars, or other meetings sponsored or co-sponsored by NASA.

- SPECIAL PUBLICATION. Scientific, technical, or historical information from NASA programs, projects, and missions, often concerned with subjects having substantial public interest.

- TECHNICAL TRANSLATION. Englishlanguage translations of foreign scientific and technical material pertinent to NASA's mission.

For more information about the NASA STI program, see the following:

- Access the NASA STI program home page at http://www.sti.nasa.gov

- E-mail your question to help@sti.nasa.gov

- $\quad$ Fax your question to the NASA STI Information Desk at 757-864-6500

- Telephone the NASA STI Information Desk at 757-864-9658

- Write to:

NASA STI Program

Mail Stop 148

NASA Langley Research Center Hampton, VA 23681-2199 
NASA/TM—2019-219978

AIAA-2019-0325

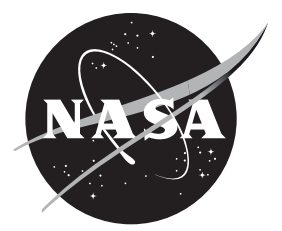

\section{Improvements to an Explicit Algebraic Stress Model for Turbulent Jet Mixing Predictions}

Nicholas J. Georgiadis and Dennis A. Yoder

Glenn Research Center, Cleveland, Ohio

Prepared for the

2019 Science and Technology Forum (SciTech)

sponsored by the American Institute of Aeronautics and Astronautics

San Diego, California, January 7-11, 2019

National Aeronautics and

Space Administration

Glenn Research Center

Cleveland, Ohio 44135 
This work was sponsored by the Transformative Aeronautics Concepts Program.

Level of Review: This material has been technically reviewed by technical management.

Available from

NASA STI Program

Mail Stop 148

NASA Langley Research Center

Hampton, VA 23681-2199
National Technical Information Service 5285 Port Royal Road Springfield, VA 22161 703-605-6000

This report is available in electronic form at http://www.sti.nasa.gov/ and http://ntrs.nasa.gov/ 


\title{
Improvements to an Explicit Algebraic Stress Model for Turbulent Jet Mixing Predictions
}

\author{
Nicholas J. Georgiadis and Dennis A. Yoder \\ National Aeronautics and Space Administration \\ Glenn Research Center \\ Cleveland, Ohio 44135
}

\begin{abstract}
Modifications to key coefficients in a $k-\epsilon$ based explicit algebraic stress model (EASM) are examined with the objective of improving the prediction of turbulent jet flows. The pressure strain coefficient, $C_{2}$ and the turbulent diffusion coefficients, $\sigma_{k}$ and $\sigma_{\epsilon}$ were investigated. For a series of benchmark subsonic jets at heated and unheated conditions, lowering $C_{2}$ from the default value of 0.36 to 0.10 resulted in a significant improvement in the jet mixing, when compared to experimental data. Changing $\sigma_{k}$ and $\sigma_{\epsilon}$ from default values of 1.00 and 1.4489 , respectively, to 0.50 and 0.7244 , respectively, improved the initial mixing rate, while reducing the farfield mixing rate and the peak turbulent kinetic energy along the centerline. A high-speed mixing layer was also investigated for performance of baseline and modified EASM coefficients, with similar results as for the jet cases. A flat plate boundary layer was briefly examined to determine the effects of changing the coefficients on the turbulent skin friction coefficient. The change to the pressure strain coefficient, $C_{2}=0.10$ is recommended for future EASM calculation of jets flow; however, it is also recommended that the diffusion coefficients remain at their default values.
\end{abstract}

\section{Nomenclature}

mixing layer thickness $=$ distance between transverse positions where $\mathrm{u}=U_{1}-0.1 \Delta U$

and $\mathrm{u}=U_{2}+0.1 \Delta U$

$b_{i j} \quad$ Reynolds stress anisotropy tensor

$C_{f} \quad$ skin friction coefficient

D jet diameter

$\mathcal{D}_{i j} \quad$ diffusion of turbulent stress

$k$ turbulent kinetic energy

$M_{a} \quad$ jet acoustic Mach number

$M_{c} \quad$ convective Mach number

$P_{T} \quad$ stagnation pressure

$P_{\infty} \quad$ ambient static pressure

$\mathcal{P}_{i j} \quad$ production of turbulent stress

$\mathcal{P} \quad$ production of turbulent kinetic energy

$R e_{x} \quad$ plate Reynolds number

$S_{i j} \quad$ rate of strain tensor

$t \quad$ time

$T_{t} \quad$ stagnation temperature

$U_{1} \quad$ freestream velocity for mixing layer high-speed stream $=700 \mathrm{~m} / \mathrm{s}$

$U_{2} \quad$ freestream velocity for mixing layer low-speed stream $=399 \mathrm{~m} / \mathrm{s}$

$U_{j} \quad$ jet exit velocity

$u_{i} \quad$ velocity vector

$u^{\prime}, v^{\prime}, w^{\prime} \quad$ fluctuating velocity components 


$\begin{array}{ll}W_{i j} & \text { vorticity tensor } \\ x, y, z & \text { Cartesian coordinates } \\ y_{0} & \text { effective centerline of the mixing layer } \\ \Delta U & \text { difference in freestream velocities for mixing layer }=U_{2}-U_{1}=301 \mathrm{~m} / \mathrm{s} . \\ \epsilon & \text { turbulent dissipation rate } \\ \kappa & \text { Von Karman constant } \\ \mu & \text { dynamic viscosity } \\ \mu_{t} & \text { dynamic eddy viscosity } \\ \omega & \text { specific turbulent dissipation rate } \\ \Pi_{i j} & \text { pressure strain correlation tensor } \\ \Pi_{i j}^{D} & \text { deviatoric pressure strain correlation tensor } \\ \rho & \text { density } \\ \tau & \text { turbulent time scale } \\ \tau_{i j}^{T} & \text { turbulent stress tensor }\end{array}$

\section{Introduction}

Improvement in the prediction of turbulent flows has arguably been the pacing technology gap in computational fluid dynamics (CFD) codes for several decades. The practical state-of-the-art for most engineering analyses is the Reynolds-averaged Navier-Stokes (RANS) approach. In recent years, research to improve turbulent flow prediction accuracy has focused on Large Eddy Simulation (LES) based methods. ${ }^{1}$ For complex problems at high Reynolds numbers where wall boundary layers are the dominant flow feature, RANS based methods are still required for most engineering analyses. Hybrid RANS-LES methods have become popular in the past decade, especially for flows where the wall-bounded regions are clearly demarcated from free shear layers, or where massive flow separation is a dominant flow feature. In these situations, RANS is used in the attached wall boundary layer regions, while LES is used elsewhere.

LES has already demonstrated promise for certain classes of flows, primarily where wall boundary layers are of secondary importance. Jet flows and the noise emitted by jets is one such example where LES has seen significant model development and usage becomes a more practical option. ${ }^{2-4}$ As computer technology continues to advance, the focus of CFD development and usage will continue to move towards LES-based methods for jet flow aerodyanmics and aeroacoustics. However, there is still a need for less costly methods to enable more rapid concept screening and evaluation, based upon RANS techniques for jet flow predictions. Ongoing efforts in RANS-based acoustic analogy methods, such as that described in Ref. 5, have demonstrated good engineering accuracy at much lower cost than that required for an LES of the same configuration. The acoustic analogy predictions are only as good as the underlying RANS prediction, and turbulence model employed. For jet flows, two-equation models, especially $k-\omega$ and $k-\epsilon$ formulations, which are linear eddy viscosity models employing the Boussinesq approximation, are typically used because of their relative accuracy and because they directly solve for the turbulent kinetic energy, $k$, and a turbulent length scale, which are quantities required by the acoustic analogy approach. ${ }^{6}$

Newer acoustic analogy efforts such as that detailed in Ref. 5 are enabling consideration of turbulent flow anisotropy, through the use of explicit algebraic stress models (EASMs). EASM approaches solve an underlying linear two-equation model, but then employ additional algebraic expressions for the individual normal and shear stresses. In this paper, we examine a $k-\epsilon$ based EASM, both in original form and with modifications to improve prediction of jet flows.

\section{Linear Eddy-Viscosity Model Calibration for Jet Flows}

Calibration of two-equation Boussinesq turbulence models has typically been targeted toward obtaining the proper behavior of the log-layer region of the boundary layer as well as the decay of homogeneous or isotropic turbulence. As discussed by Papp and Dash, ${ }^{7}$ and Yoder, ${ }^{8}$ turbulence model coefficients that work well for wall boundary layers tend to underpredict the level of turbulent shear in jets and mixing layers. The problem is one that has been recognized for some time. Bradshaw ${ }^{9}$ explains that the coefficients used in the modeling terms will only assume constant values in the unlikely event that the modeled term exactly correlates with the physical term it represents. More likely, these coefficients will be different for different flows, and may 
vary from point to point within the same flow. Numerous attempts have been made to improve jet flow predictions using the "standard" high Reynolds number two-equation $k-\epsilon$ model. ${ }^{10-12}$

Kenzakowski ${ }^{13}$ decreased the $\sigma_{k}$ diffusion coefficient in the turbulent kinetic energy transport equation from 1.0 to 0.75 . Engblom, et al. ${ }^{14}$ formulated a variable diffusion coefficient for both $\sigma_{k}$ and $\sigma_{\epsilon}$ that likewise reduced the effective coefficient values for axisymmetric jet flows. In both cases, reducing these coefficient values resulted in faster transport of turbulent kinetic energy toward the jet axis, as well as an upstream shift in the end of the potential core. Thies and $\operatorname{Tam}^{15}$ went to the extreme and recalibrated all of the $k-\epsilon$ coefficients to provide more accurate prediction of the jet mean velocity, but the model underpredicts the peak centerline turbulent kinetic energy. These models were compared for reference round jets in Ref. 16. Birch, et al. ${ }^{17}$ suggested that different constants are needed in the near field and far field of the jet to account for the change in turbulence structure as it transitions from the planar-like mixing layer near the nozzle lip to the axisymmetric mixing region in the far field. To accomplish this, they proposed a zonal model that applies one set of coefficients in the region upstream of the end of the jet potential core and another set of coefficients downstream. However, the exact switching location is user specified, thus limiting the generality of the model.

Additional correction terms beyond model coefficient adjustment have been proposed to account for the effects of: dilatation dissipation compressibility, ${ }^{18-20}$ round jet vortex stretching, ${ }^{21}$ and jet heating. ${ }^{22,23}$ In many cases, the physical justification used in the formulation of these models has since shown to be much weaker than first thought. However, such models continue to be used as "empirical corrections" simply because they happen to shift the results in the desired direction.

\section{Explicit Algebraic Model Calibration for Jet Flows}

Although algebraic stress and differential Reynolds stress transport models incorporate additional physics into the modeled terms, they too tend to be primarily calibrated for wall-bounded flow. References 24-26 demonstrate a consistent under-prediction of jet mixing rates when using algebraic stress models. Yoder ${ }^{8}$ compared planar mixing layer results from Boussinesq, algebraic stress, and differential Reynolds stress models using a common set of standard model coefficients. While the algebraic and differential stress model results were similar, both predicted a peak shear stress that was in worse agreement with the experiment and at least ten percent lower than the Boussinesq model. This might be attributable to the different treatment of the turbulent stress as well as the use of that stress to compute the turbulence production.

Papp, Kenzakowski, and Dash ${ }^{26}$ performed a recalibration of an algebraic stress model to improve jet flow predictions. They found that reducing the $C_{2}$ coefficient in the Speziale, Sarkar, and Gatski ${ }^{27}$ model terms for the pressure-strain correlation tensor from its original value of 0.36 to 0.25 resulted in much closer agreement with the peak shear stress of both experimental data and the Boussinesq model. In the planar mixing layer study of Yoder, ${ }^{8}$ a sensitivity analysis was conducted for multiple model coefficients. Those results also indicate that reducing $C_{2}$ has the strongest effect on increasing the turbulent shear stress and mixing layer growth rate, with a value of 0.10 providing the best agreement with the available data. Adjustment of the other pressure-strain coefficients in the algebraic stress model may be used to improve the anisotropic distribution of the turbulence normal stresses.

\section{EASM Formulation}

In this section, we provide key details of the $k-\epsilon$ based EASM used in this paper. A complete description of this model is given in Yoder. ${ }^{30}$

\section{Algebraic Stress model}

Derivation of an algebraic stress model follows from simplification of a differential Reynolds stress model, such as that of Launder, Reece, and Rodi, ${ }^{31}$ having the form:

$$
\frac{\partial}{\partial t}\left(-\tau_{i j}^{T}\right)+\frac{\partial}{\partial x_{k}}\left(-\tau_{i j}^{T} \tilde{u}_{k}\right)=\mathcal{P}_{i j}+\mathcal{D}_{i j}+\Pi_{i j}-\frac{2}{3} \rho \epsilon \delta_{i j}
$$

where $\mathcal{P}_{i j}$ is the exact turbulent production term, $\mathcal{D}_{i j}$ is the turbulent stress diffusion, and $\Pi_{i j}$ is the pressure-strain correlation tensor. It is this pressure-strain term which functionally provides most of the 
anisotropy capability of a Reynolds stress model, and which linear eddy viscosity models have no capability to provide. A typical form of the deviatoric pressure strain tensor is as shown in Eqn. 2.

$$
\begin{aligned}
\frac{\Pi_{i j}^{D}}{\rho \epsilon} & =-\left(C_{1}^{0}+C_{1}^{1} \frac{\mathcal{P}}{\rho \epsilon}\right) b_{i j}+C_{2} \frac{k}{\epsilon}\left(S_{i j}-\frac{1}{3} S_{k k} \delta_{i j}\right) \\
& +C_{3} \frac{k}{\epsilon}\left(b_{i j} S_{j k}+b_{j k} S_{i k}-\frac{2}{3} b_{m m} S_{m m} \delta_{i j}\right)+C_{4} \frac{k}{\epsilon}\left(b_{i k} R_{j k}+b_{j k} R_{i k}\right)
\end{aligned}
$$

Using Eqn. 2, the weak equilibrium assumption for the turbulence anisotropy, and a simplification for turbulent diffusion, Eqn. 1 can be expressed in a tensor basis expression that is then used for the EASM:

$$
\begin{array}{r}
\tau_{i j}^{T}=-\frac{2}{3} \rho k \delta_{i j}+2 \mu_{t}^{*}\left\{S_{i j}-\frac{1}{3} S_{k k} \delta_{i j}+\left[a_{2} a_{4}\left(S_{i k} W_{k j}-W_{i k} S_{k j}\right)\right.\right. \\
\left.\left.-2 a_{3} a_{4}\left(S_{i k} S_{k j}-\frac{1}{3} S_{k l} S_{l k} \delta_{i j}\right)\right]\right\}
\end{array}
$$

where $S_{i j}$ is:

$$
S_{i j}=\frac{1}{2}\left(\frac{\partial u_{i}}{\partial x_{j}}+\frac{\partial u_{j}}{\partial x_{i}}\right)
$$

and $W_{i j}$ is:

$$
W_{i j}=\frac{1}{2}\left(\frac{\partial u_{i}}{\partial x_{j}}-\frac{\partial u_{j}}{\partial x_{i}}\right)
$$

The nonlinear eddy viscosity, $\mu_{t}^{*}$ is:

$$
\mu_{t}^{*}=C_{\mu}^{*} \rho k \tau=-\alpha_{1} \rho k
$$

and the turbulent time scale is $\tau=1 / \omega=k / \epsilon$. The quantity $\alpha_{1} / \tau$ is equivalent to $-C_{\mu}^{*}$ and is obtained from the solution to a cubic equation at every point in the flow field. The solution procedure is described in detail in Refs. 28-30.

Per Speziale, Sarkar, and Gatski, ${ }^{27}$ the pressure strain coefficients in Eqn. 2, have the following values:

$$
C_{1}^{0}=3.4 \quad C_{1}^{1}=1.8 \quad C_{2}=0.36 \quad C_{3}=1.25 \quad C_{4}=0.4
$$

The form of the $k-\epsilon$ model used as the underlying two-equation model for the EASM is:

$$
\begin{gathered}
\rho \frac{D k}{D t}=\frac{\partial}{\partial x_{j}}\left[\left(\mu+\frac{\mu_{t}^{*}}{\sigma_{k}}\right) \frac{\partial k}{\partial x_{j}}\right]+\mathcal{P}-\rho \epsilon \\
\rho \frac{D \epsilon}{D t}=\frac{\partial}{\partial x_{j}}\left[\left(\mu+\frac{\mu_{t}^{*}}{\sigma_{\epsilon}}\right) \frac{\partial \epsilon}{\partial x_{j}}\right]+C_{\epsilon 1} f_{1} \frac{\epsilon}{k} \mathcal{P}-C_{\epsilon 2} f_{2} \frac{\epsilon^{2}}{k}
\end{gathered}
$$

where the production of $k$ is given by:

$$
\mathcal{P}=\tau_{i j}^{T} \frac{\partial u_{i}}{\partial x_{j}} \approx 2 \mu_{t}^{*} S_{i j} S_{i j}
$$

where

$$
\begin{array}{lcc}
f_{1}=1.0 & f_{2}=\left[1-\exp \left(-\frac{R_{y}}{10.8}\right)\right] & R_{y}=\sqrt{k} y / \nu \\
\kappa=0.41 & C_{\mu}=0.0885 & C_{\epsilon 1}=1.44 \\
C_{\epsilon 2}=1.83 & \sigma_{k}=1.0 & \sigma_{\epsilon}=1.4489
\end{array}
$$


Yoder $^{8}$ performed an extensive sensitivity study on the effects of the pressure strain coefficients for an incompressible planar shear layer, and found that the most significant improvement to the mixing rate and turbulent stresses was provided by changing the $C_{2}$ coefficient from 0.36 to 0.10 . In this paper, effects of this change to $C_{2}$ are considered for a series of benchmark round jet cases. Effects of the diffusion coefficients, $\sigma_{k}$ and $\sigma_{\epsilon}$, in the underlying k- $\epsilon$ model are also examined. These two sets of coefficients are also studied for a high speed mixing layer and incompressible flat plate.

Comparisons of solutions obtained with the baseline and modified EASMs are made with the Menter Shear Stress Transport (SST) $k-\omega$ turbulence model. ${ }^{32-34}$ This linear-eddy viscosity model has been one of the most successful and popular RANS turbulence models during the past two decades. A large reason for its success is in predicting wall bounded flows for a variety of flow conditions. It is a two-layer model, with inner model based on the Wilcox $k-\omega^{35,36}$ formulation near walls and a transformed $k-\epsilon$ model away from walls and in free shear layers based on the formulation of Refs. 10-12, which is typically referred to as the standard $k-\epsilon$ model. It has closure coefficients very similar to that described for the $k-\epsilon$ model central to the EASM model considered here. Also central to the SST model is the use of a limiter, which in the standard published version of the model prevents the turbulent shear stress from exceeding 0.31 times the turbulent kinetic energy in the inner part of a boundary layer. For jet flow regions, this limiter is not employed.

\section{Results}

\section{Round Jets}

In this section, we first examine the round jets tested by Bridges and Wernet. ${ }^{37}$ In Ref. 37, several sets of experimental data in addition to that of the authors, were carefully considered and compiled into a set of "consensus data" for turbulent round jets. Three of these cases, all corresponding to subsonic round jets, have been included on the NASA Turbulence Modeling Resource website described in Ref. 38 and have been examined here. In Bridges and Wernet, ${ }^{37}$ the authors categorize the jets by a parameter known as the jet acoustic Mach number, $M_{a}$, which is equal to the jet exit velocity divided by the freestream speed of sound. The first case has $M_{a}=0.5$ and is unheated (cold); the second has the same $M_{a}=0.5$ but the jet is heated such that the jet exit temperature is 1.75 times that of the ambient; and the third is an unheated jet with $M_{a}=0.9$. In the experiments, the jets exhausted into ambient air. In the computations described here, a very low freestream Mach number $=0.01$ was specified. This procedure has regularly been used to enable the flow solver to converge, while having virtually no effect on mixing behavior of the jets.

A comparison of jet centerline velocity and turbulent kinetic energy from RANS solutions and experimental data is provided in Fig. 1. For each of the three jet cases just discussed, there are three solutions provided: One with the Menter SST (linear eddy-viscosity) $k-\omega$ model, the second with unmodified $k-\epsilon$ EASM, with key pressure strain coefficient, $C_{2}$, set to 0.36 , and a third $k-\epsilon$ EASM solution where $C_{2}$ is reduced to 0.10. It may be observed that none of the solutions provide excellent agreement with the experimental data, but the unmodified $k-\epsilon$ EASM provides the worst delay in initial jet mixing for all of the three jet flow set points. Examining the experimental data alone, it may be noted that the heated $M_{a}=0.5$ case mixes the fastest, followed by the cold $M_{a}=0.5$ case, and the $M_{a}=0.9$ case has the longest potential core and slowest initial mixing rate. It is believed that for $M_{a}=0.9$, some compressibility effects are beginning to slow down the rate of mixing in the jet shear layer, relative to the more nearly incompressible $M_{a}=0.5$ case. Returning to the RANS solutions, it may be observed that the modified EASM with $C_{2}$ reduced to 0.10, substantially improves the mixing rate, and provides close agreement with the Menter SST $k-\omega$ solutions. While not shown here, additional variations in $C_{2}$ were considered, with the general trend being an increased initial mixing rate (and correspondingly shorter jet potential core) as $C_{2}$ was reduced. Solutions obtained with $C_{2}=0.05$ exhibited only slightly more mixing than the $C_{2}=0.10$ cases. These results agree with those suggested by Yoder, ${ }^{8}$ where $C_{2}=0.10$ was found to improve mixing for an incompressible planar shear layer.

The next sets of comparisons consider variations in the $k-\epsilon$ coefficients, which as discussed in the introduction, have been used for linear two-equation models to improved jet mixing predictions. The results shown in Fig. 2 use the default pressure strain coefficient setting, $C_{2}=0.36$, but compare default settings for the $k-\epsilon$ diffusion coefficients, $\sigma_{k}=1.00$ and $\sigma_{\epsilon}=1.4489$ to settings corresponding to half of these values, $\sigma_{k}=0.50$ and $\sigma_{\epsilon}=0.7244$. Examining Eqns. 7 and 8, it may be observed that this effectively doubles the contribution of the turbulent diffusion terms, because these diffusion coefficients are in the denominators. The velocity profiles in Fig. 2(a) show that relative to the baseline EASM with standard diffusion coefficients, 
the cases with diffusion coefficients dropped by half (and recall increased turbulent diffusion) have a more gradual rounding of the end of the potential core and shorter potential core, improving agreement with data. The mixing rate further downstream is reduced. Examining the turbulent kinetic energy profiles in Fig. 2 (b), the peak turbulent kinetic energy along the centerline is also reduced.

The same two sets of diffusion coefficients are examined while reducing the pressure strain coefficient to $C_{2}=0.10$ in Fig. 3. For the two cold cases at $M_{a}=0.5$ and $M_{a}=0.9$, the centerline velocities obtained with $C_{2}=0.10$ and diffusion coefficients set to half of the default values provide close agreement with the experimental data. As was the case for $C_{2}=0.36$, the potential core is shortened, the velocity profile near the end of the potential core is more rounded, while the mixing rate further downstream (near $x / D=20$ ) is reduced. A similar trend is also observed for the turbulent kinetic energy profiles.

A final set of comparisons with a fixed setting for $C_{2}=0.10$ is provided in Fig. 4. Here, the lowered diffusion coefficients $\sigma_{k}=0.50$ and $\sigma_{\epsilon}=0.7244$ are compared with the settings recommended by Thies and $\operatorname{Tam}^{15}$ where $\sigma_{k}=0.3244$ and $\sigma_{\epsilon}=0.377$. The centerline velocity and turbulent kinetic energy profiles are generally similar, with the Tam-Thies settings in general resulting in delayed mixing relative to solutions obtained with $\sigma_{k}=0.50$ and $\sigma_{\epsilon}=0.7244$.

\section{High Speed Mixing Layer}

The primary objective of the EASM parameter investigations considered in this paper was to improve calculation of jet flows. To further examine the model for a highly-respected free shear layer mixing data set, currently being used in the NASA Transformative Tools and Technology Project to evaluate RANS and LES approaches, we examine a high-speed planar mixing layer investigated by Goebel and Dutton. ${ }^{39,40}$ Specifically, we consider Case 2 of their experiments, where the highest speed stream had a Mach number of 1.91 , stagnation temperature, $T_{t}=578 \mathrm{~K}$, and freestream velocity of $700 \mathrm{~m} / \mathrm{s}$. The lower speed stream had a Mach number of 1.36 , stagnation temperature, $T_{t}=295 \mathrm{~K}$, and freestream velocity of $399 \mathrm{~m} / \mathrm{s}$. The convective Mach number of this case, $M_{c}$ was 0.46 .

We compare data from the experiments with RANS solutions obtained with (1) Menter SST lineareddy viscosity model, (2) baseline $k-\epsilon$ EASM, (3) $k-\epsilon$ EASM with $C_{2}$ reduced to 0.10 (this is referred to as "EASM-P.S." in the following figures), and (4) $k-\epsilon$ EASM with $C_{2}=0.10$, and modified diffusion coefficients, $\sigma_{k}=0.50$ and $\sigma_{\epsilon}=0.7244$ (this is referred to as "EASM-Diff. and P.S." in the following figures). The nomenclature of "P.S." refers to the pressure strain coefficient, $C_{2}$ being reduced to 0.10 . Three axial stations in the mixing layer are considered: the first at $\mathrm{X}=150 \mathrm{~mm}$ which is near the end of the development or non-equilibrium region according to the experimental findings, and the next two stations are at $\mathrm{X}=250$ $\mathrm{mm}$ and $\mathrm{X}=350 \mathrm{~mm}$, believed to be in the more self-similar linear growth region.

The velocity profiles shown in Fig. 5 show that generally the best solution is that produced by the EASM solution with $C_{2}=0.10$ and diffusion coefficients unmodified from the original form. All of the EASM solutions show a more gradual rounding at each edge of the shear layer relative to the Menter SST solution. The turbulent shear stress comparisons in Fig. 6 show the highest predicted turbulent shear stress for the Menter SST model. The baseline EASM solution and that with modifications to both $C_{2}$ and diffusion coefficients yield very similar turbulent shear stresses. Reducing $C_{2}$ from 0.36 to 0.10 increases the turbulence while the extra turbulent diffusion from using $\sigma_{k}=0.50$ and $\sigma_{\epsilon}=0.7244$ tends to more rapidly spread the turbulence away from the center of the shear layer where the turbulent shear stress peaks.

The axial and transverse turbulent normal stresses are shown in Figs. 7 and 8 respectively. In general, the trend is similar to that of the turbulent shear stress. Note that the Menter SST model is unable to differentiate between the axial and transverse turbulent normal stresses due to limitations of its reliance on the Boussinesq approximation. In particular, the transverse normal stress is significantly overpredicted with the Menter SST model. Overall, the $k-\epsilon$ EASM solution with $C_{2}$ lowered to 0.10 but diffusion coefficients unchanged from their original form $\left(\sigma_{k}=1.00\right.$ and $\left.\sigma_{\epsilon}=1.4489\right)$ yields the best agreement with all of the data for this high-speed mixing layer case.

The mixing layer thicknesses obtained from all of the solutions are compared with experimental data in Fig. 9. Note that this mixing layer thickness is defined as the distance between transverse positions where $\mathrm{u}=U_{1}-0.1 \Delta U$ and $\mathrm{u}=U_{2}+0.1 \Delta U$. Because the mixing layer is in an enclosed duct between two streams that are supersonic, there are a series of weak oblique shock waves that result in slight changes in the edge velocities, $U_{1}$ and $U_{2}$, and the waviness in all of the solutions and experimental data for the mixing layer thicknesses shown in Fig. 9. It is clear that the solution with "EASM-P.S." results in greater mixing than the baseline $k-\epsilon$ EASM, while the $k-\epsilon$ EASM with $C_{2}=0.10$ and modified diffusion coefficients reduces 
the mixing rate. The SST solution yields the highest mixing layer growth which follows from shear stress levels (see Fig. 6) also being highest from the SST solution.

\section{Flat Plate Boundary Layer}

While the focus of this paper is on jet and free shear layer mixing away from walls, most jet flows originate from nozzles where accurate calculation of wall boundary layer regions is also important. To only briefly consider effects of these EASM variations on boundary layer calculations, a nearly incompressible flat plate flow was investigated with freestream Mach number set to 0.2 . For this case, the grid and boundary conditions that are available on the turbulence modeling resource website described in Ref. 38 for a turbulent flat plate were employed. The grid was previously verified to yield grid independent solutions.

The skin friction coefficient along the flat plate is shown in Fig. 10. The solutions are compared with data of Wieghardt and Tillman. ${ }^{41}$ The same variation in the $k-\epsilon$ EASM parameters as discussed in the previous section, with the same corresponding description of each case in the legend, is shown in Fig. 10. It may be observed that except for the EASM solution where the diffusion coefficients were reduced, that the other EASM solutions and SST model solution yield very similar predictions of turbulent skin friction along the flat plate. The EASM solution with $C_{2}=0.10$ has slightly increased skin friction relative to the baseline case. The most notable result, however, is that reducing the diffusion coefficients, which we recall increases the turbulent diffusion, has an adverse effect on the boundary layer development. This is the result of too much diffusion of turbulent kinetic energy away from the near wall region. In terms of recommending a parameter set for the $k-\epsilon$ EASM that would provide improved predictions for jet or free shear layer mixing flows while not degrading wall boundary layer predictions, reducing the pressure strain coefficient, $C_{2}$, to 0.10 while leaving the diffusion coefficients unchanged, seems like the optimal choice based on the results considered for these cases.

\section{Conclusions}

While it is recognized that Large Eddy Simulation (LES) will become increasingly more popular for jet flow simulations in the future, there is still need for more accurate Reynolds-averaged Navier-Stokes (RANS) computational approaches, which are able to provide more rapid turnaround of solutions. These RANS solutions are important not only to assess the aerodynamics of jet flowfields but also as input to acoustic analogy approaches for predicting jet noise. The practical state-of-the-art for RANS jet flow computations has been linear two-equation eddy-viscosity models, especially $k-\omega$ and $k-\epsilon$ formulations. However, despite several attempts to develop corrections to such two-equation models to improve jet flow predictions, the success and generality of these corrections has been limited. These models also have no provision to handle turbulence anisotropy. Newer acoustic analogy approaches are trying to include effects of turbulence anisotropy, and as a result, the linear two-equation models are unable to provide the flow quantities needed as input.

Explicit algebraic stress models (EASMs) have the ability to include effects of turbulence anisotropy, and are not significantly more computationally expensive than linear two-equation models. Like the linear models, they require an underlying two-equation RANS model, and then solve additional algebraic expressions to obtain the turbulent stress components. Previous investigations of $k-\omega$ and $k-\epsilon$ based EASMs have actually indicated worse predictions of low order flowfield statistics, such as jet flow velocity, than the linear models. There have been a small number of attempts to improve the rate of jet mixing using EASMs. In this paper, the effect of a key pressure strain coefficient, $C_{2}$, and the turbulent diffusion coefficients, $\sigma_{k}$ and $\sigma_{\epsilon}$, were investigated.

For a series of subsonic jets at heated and unheated conditions, lowering $C_{2}$ from the default value of 0.36 to 0.10 , the value optimized by Yoder $^{8}$ for an incompressible mixing layer, resulted in a significant improvement in the jet mixing, when compared to experimental data. Reducing $\sigma_{k}$ and $\sigma_{\epsilon}$ by a factor of two from default values of 1.00 and 1.4489 , respectively, to 0.50 and 0.7244 , respectively, improved the initial mixing rate, but reduced the peak turbulent kinetic energy along the centerline, and also reduced the farfield mixing rate. Lowering these turbulent diffusion coefficients by a factor of two increased the turbulent diffusion, which helps to shorten the potential core of the jets by spreading the initially thin mixing layer, but beyond this region, the diffusion is too high, adversely affecting the subsequent mixing in the jet.

A high speed mixing layer was investigated next, specifically Case 2 from the Goebel and Dutton ex- 
periments, with two supersonic streams at a convective Mach number, $M_{c}$, of 0.46 . For these cases, the clear advantages of the EASMs over linear models such as the Menter SST $k-\omega$ model, to more accurately reproduce the ratio of axial to transverse normal turbulent stresses, was demonstrated. The EASM solution employing $C_{2}=0.10$ and no change to the default turbulent diffusion coefficients yielded the overall best predictions of the mixing layer velocities and turbulent statistics. Finally, an incompressible flat plate boundary layer was investigated. While not a free shear layer mixing case as was the focus of this paper, the flat plate boundary layer was briefly examined to determine the effects of the EASM coefficient variations on wall bounded flow regions. It was determined that changing $C_{2}$ from the default value of 0.36 to 0.10 , had no adverse effect on the turbulent skin friction coefficient, while changing the diffusion coefficients results in a significant degradation in the calculated turbulent skin friction.

In conclusion, the change to the pressure strain coefficient to $C_{2}=0.10$ is recommended for future EASM calculations of jet flow. This result was applied to three-stream coannular and offset stream nozzle flowfields in Leib et $\mathrm{al}^{5}$ with significant improvements over the Menter SST $k-\omega$ model and baseline $k-\epsilon$ EASM for both the aerodynamic flowfields and the predicted noise, using an acoustic analogy solver. It is recommended that the diffusion coefficients not be changed from their default values. If a generalized method to employ reduced diffusion coefficients near the origin of the jet mixing region could be constructed, there may be future improvements, but previous similar attempts with linear two-equation models were not successfully generalized.

\section{References}

\footnotetext{
${ }^{1}$ Slotnick, J., Khodadoust, A., Alonso, J., Darmofal, D., Gropp, W., Lurie, E., and Mavripilis, D., "CFD Vision 2030 Study: A Path to Revolutionary Computational Aerosciences," NASA CR 2014-218178, March 2014.

${ }^{2}$ Tucker, P., "The LES model's role in jet noise," Progress in Aerospace Sciences, Vol. 44, 2008, pp. 427-436.

${ }^{3}$ Bodony, D. and Lele, S., "Current Status of Jet Noise Predictions Using Large-Eddy Simulation," AIAA Journal, Vol. 46, No. 2, 2008, pp. 364-380.

${ }^{4}$ Georgiadis, N. J. and DeBonis, J. R., "Navier-Stokes Analysis Methods for Turbulent Jet Flows with Application to Aircraft Exhaust Nozzles," Progress in Aerospace Sciences, Vol. 42, 2006, pp. 377-418.

${ }^{5}$ Leib, S., Georgiadis, N., and Yoder, D., "Reynolds-Averaged Navier-Stokes Solutions and Noise Predictions for ThreeStream Jets," AIAA Paper 2016-1882, Jan. 2016.

${ }^{6}$ Kenzakowski, D. and Papp, J., "EASM/J Extensions and Evaluation for Jet Noise Prediction," AIAA Paper 2005-0419, Jan. 2005.

${ }^{7}$ Papp, J. and Dash, S., "Turbulence Model Unification and Assessment for High-Speed Aeropropulsive Flows," AIAA Paper 2001-0880, Jan. 2001. 2005.

${ }^{8}$ Yoder, D. A., Algebraic Reynolds Stress Modeling of Planar Mixing Layer Flows, Ph.D. thesis, University of Cincinnati,

${ }^{9}$ Bradshaw, P., "Turbulence Modeling with Application to Turbomachinery," Progress in Aerospace Sciences, Vol. 32, 1996, pp. 575-624.

${ }^{10}$ Launder, B. and Sharma, B., "Application of the Energy-Dissipation Model of Turbulence to the Calculation of Flow Near a Spinning Disc," Letters in Heat and Mass Transfer, Vol. 1, 1974, pp. 131-138.

${ }^{11}$ Jones, W. and Launder, B., "The Prediction of Laminarization with a Two-Equation Model of Turbulence," International Journal of Heat and Mass Transfer, Vol. 15, 1972, pp. 301-314.

12 Jones, W. and Launder, B., "The Calculation of Low-Reynolds-Number-Phenomena with a Two-Equation Model of Turbulence," International Journal of Heat and Mass Transfer, Vol. 16, 1973, pp. 1119-1130.

${ }^{13}$ Kenzakowski, D., Kannepalli, C., and Brinckman, K., "Computational Studies Supporting Concepts for Supersonic Jet Noise Reduction," AIAA Paper 2004-0518, Jan. 2004.

${ }^{14}$ Engblom, W. A., Georgiadis, N. J., and Khavaran, A., "Investigation of Variable Diffusion Turbulence Model Correction for Round Jets," AIAA Paper 2005-3085, May 2005.

${ }^{15}$ Thies, A. T. and Tam, C. K. W., "Computation of Turbulent Axisymmetric and Nonaxisymmetric Jet Flows Using the $k-\epsilon$ Model," AIAA Journal, Vol. 34, 1996, pp. 309-316.

${ }^{16}$ Georgiadis, N. J., Yoder, D. A., and Engblom, W. A., "Evaluation of Modified Two-Equation Turbulence Models for Jet Flow Predictions," AIAA Journal, Vol. 44, No. 12, 2006, pp. 3107-3114.

${ }^{17}$ Birch, Stanley, F., Lyubimov, D. A., Secundov, A. N., and Yakubovsky, K. Y., "Numerical Modeling Requirements for Coaxial and Chevron Nozzle Flows," AIAA Paper 2003-3287, May 2003.

${ }^{18}$ Sarkar, S., Erlebacher, G., Hussaini, M. Y., and Kreiss, H. O., "The Analysis and Modeling of Dilatational Terms in Compressible Turbulence," Journal of Fluid Mechanics, Vol. 227, 1991, pp. 473-493.
} 
${ }^{19}$ Zeman, O., "Dilatation Dissipation: The Concept and Application in Modeling Compressible Mixing Layers," Physics of Fluids A, Vol. 2, Feb. 1990, pp. 178-188.

${ }^{20}$ Wilcox, D., "Dilatation-Dissipation Corrections for Advanced Turbulence Models," AIAA Journal, Vol. 30, No. 11, Nov. 1992, pp. 2639-2646.

${ }^{21}$ Pope, S., "An Explaination of the Turbulent Round-Jet/Plane-Jet Anomaly," AIAA Journal, Vol. 16, No. 3, Feb. 1978, pp. 279-281.

${ }^{22}$ Abdol-Hamid, K. S., Pao, S. P., Massey, S. J., and Elmiligui, A., "Temperature Corrected Turbulence Model for High Temperature Jet Flow," Journal of Fluids Engineering, Vol. 126, No. 5, 2004, pp. 844-850.

${ }^{23}$ Tam, C. K. W. and Ganesan, A., "A Modified $k-\epsilon$ Turbulence Model for Calculating the Mean Flow and Noise of Hot Jets," AIAA Journal, Vol. 42, No. 1, Jan. 2004, pp. 26-34.

${ }^{24}$ Gatski, T. B. and Speziale, C. G., "On Explicit Algebraic Stress Models for Complex Turbulent Flows," Journal of Fluid Mechanics, Vol. 254, 1993, pp. 59-78.

${ }^{25}$ Abid, R., Morrison, J. H., Gatski, T. B., and Speziale, C. G., "Prediction of Complex Aerodynamic Flows with Explicit Algebraic Stress Models," AIAA Paper 96-0565, Jan. 1996.

${ }^{26}$ Papp, J., Kenzakowski, D., and Dash, S., "Calibration and Validation of EASM Turbulence Model Jet Flowfields," AIAA Paper 2002-0855, Jan. 2002.

${ }^{27}$ Speziale, C. G., Sarkar, S., and Gatski, T. B., "Modelling the Pressure-Strain Correlation of Turbulence: An Invariant Dynamical Systems Approach," Journal of Fluid Mechanics, Vol. 227, 1991, pp. 245-272.

${ }^{28}$ Rumsey, C. L. and Gatski, T. B., "Recent Turbulence Model Advances Applied to Multielement Airfoil Computations," Journal of Aircraft, Vol. 38, No. 5, Sept. 2001, pp. 904-910.

${ }^{29}$ Rumsey, C. L., Gatski, T. B., and Morrison, J. H., "Turbulence Model Predictions of Strongly Curved Flow in a U-Duct," AIAA Journal, Vol. 38, No. 8, Aug. 2000, pp. 1394-1402.

${ }^{30}$ Yoder, D. A., "Initial Evaluation of an Algebraic Reynolds Stress Model for Compressible Turbulent Shear Flows," AIAA Paper 2003-0548, Jan. 2003

${ }^{31}$ Launder, B., Reece, G., and Rodi, W., "Progress in the Development of a Reynolds-Stress Turbulence Closure," Journal of Fluid Mechanics, Vol. 68, No. 3, 1975, pp. 537-566.

${ }^{32}$ Menter, F. R., "Two Equation Eddy-Viscosity Turbulence Models for Engineering Applications," AIAA Journal, Vol. 32, No. 8, 1994, pp. 1598-1605. 1992.

${ }^{33}$ Menter, F. R., "Improved Two Equation $k-\omega$ Turbulence Models for Aerodynamic Flows," NASA TM 103975, October

${ }^{34}$ Menter, F. R., "Zonal Two Equation $k-\omega$ Turbulence Models for Aerodynamic Flows," AIAA-93-2906, July 1993.

${ }^{35}$ Wilcox, D., "Reassessment of the Scale-Determining Equation for Advanced Turbulence Models," AIAA Journal, Vol. 26 , No. 11, Nov. 1988, pp. 1299-1310.

${ }^{36}$ Wilcox, D., "A Half Century Historical Review of the $k-\omega$ Model," AIAA Paper 91-0615, Jan. 1991.

${ }^{37}$ Bridges, J. and Wernet, M. P., "Establishing Consensus Turbulence Statistics for Hot Subsonic Jets," AIAA Paper 2010-3751, June 2010.

${ }^{38}$ Rumsey, C., Smith, B., and Huang, G., "Description of a Website Resource for Turbulence Modeling Verification and Validation," AIAA Paper 2010-4742, June 2010.

${ }^{39}$ Goebel, S. G., An Experimental Study of Compressible Turbulent Mixing Layers, Ph.D. thesis, University of Illinois at Urbana-Champaign, 1990.

${ }^{40}$ Goebel, S. and Dutton, J., "Experimental Study of Compressible Turbulent Mixing Layers," AIAA Journal, Vol. 29, No. 4, April 1991, pp. 538-546.

${ }^{41}$ Wieghardt, K. and Tillman, W., "On the Turbulent Friction Layer for Rising Pressure," NASA TM 1314, 1951. 


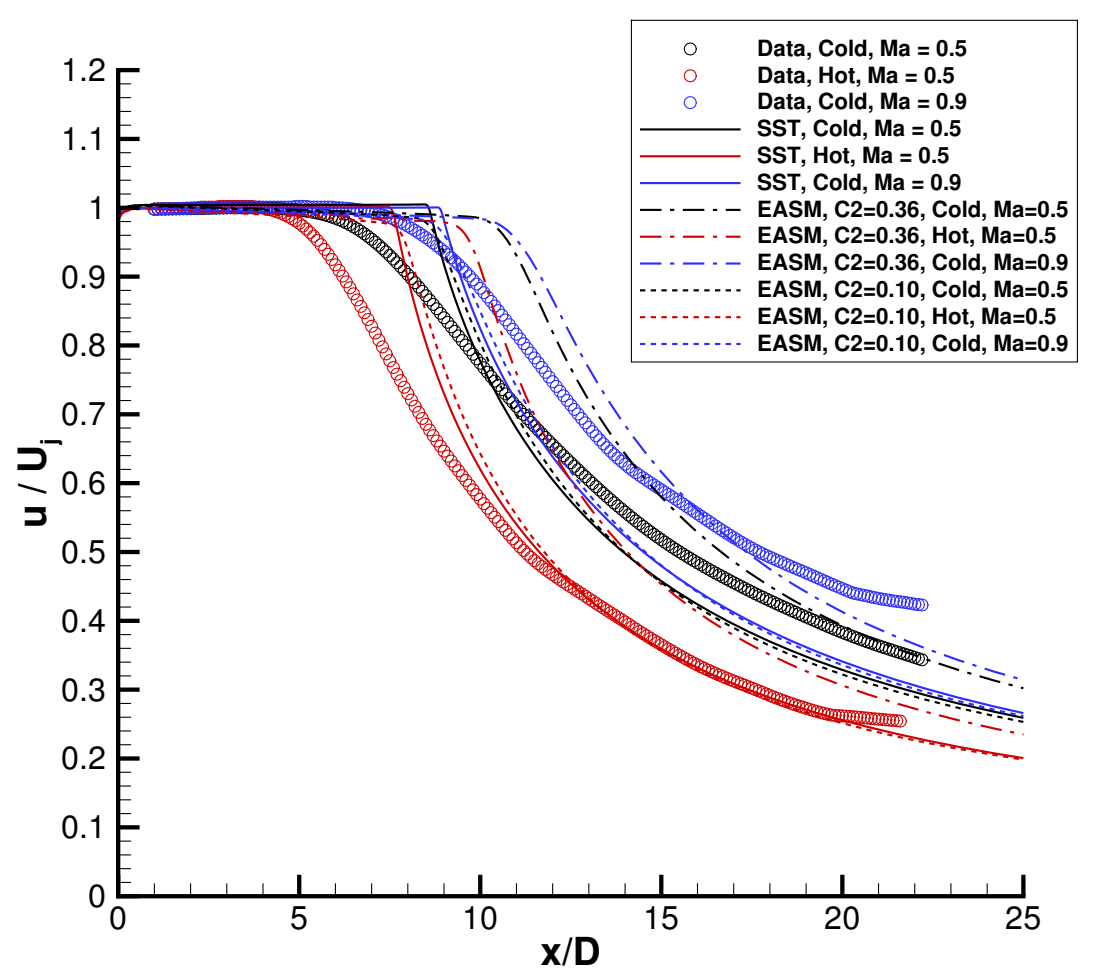

(a) Centerline velocity

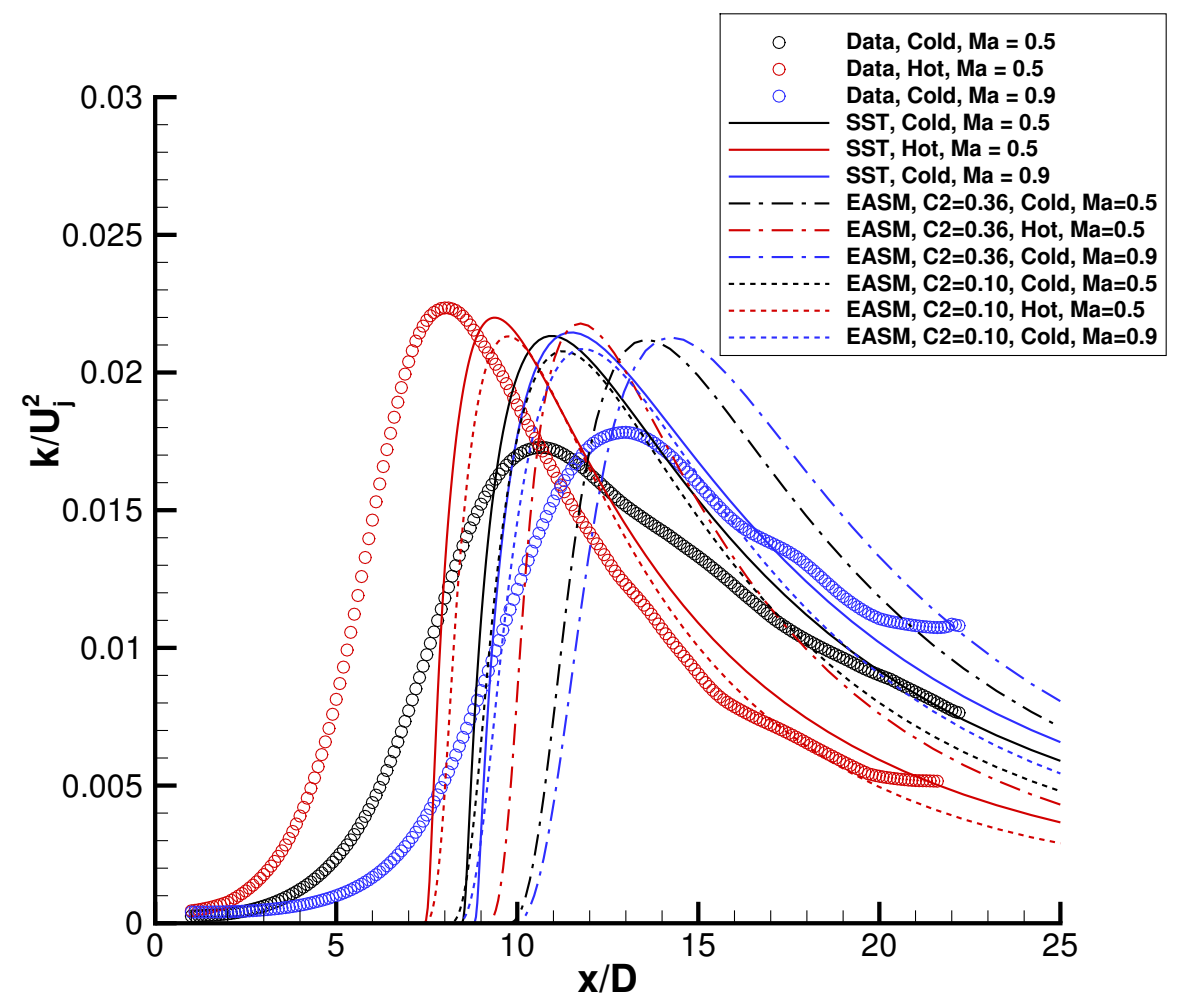

(b) Centerline turbulent kinetic energy

Figure 1. Comparison of SST(linear k- $\omega$ ), baseline k- $\epsilon$ EASM, and modified EASM with $C_{2}$ lowered to 0.10 . 


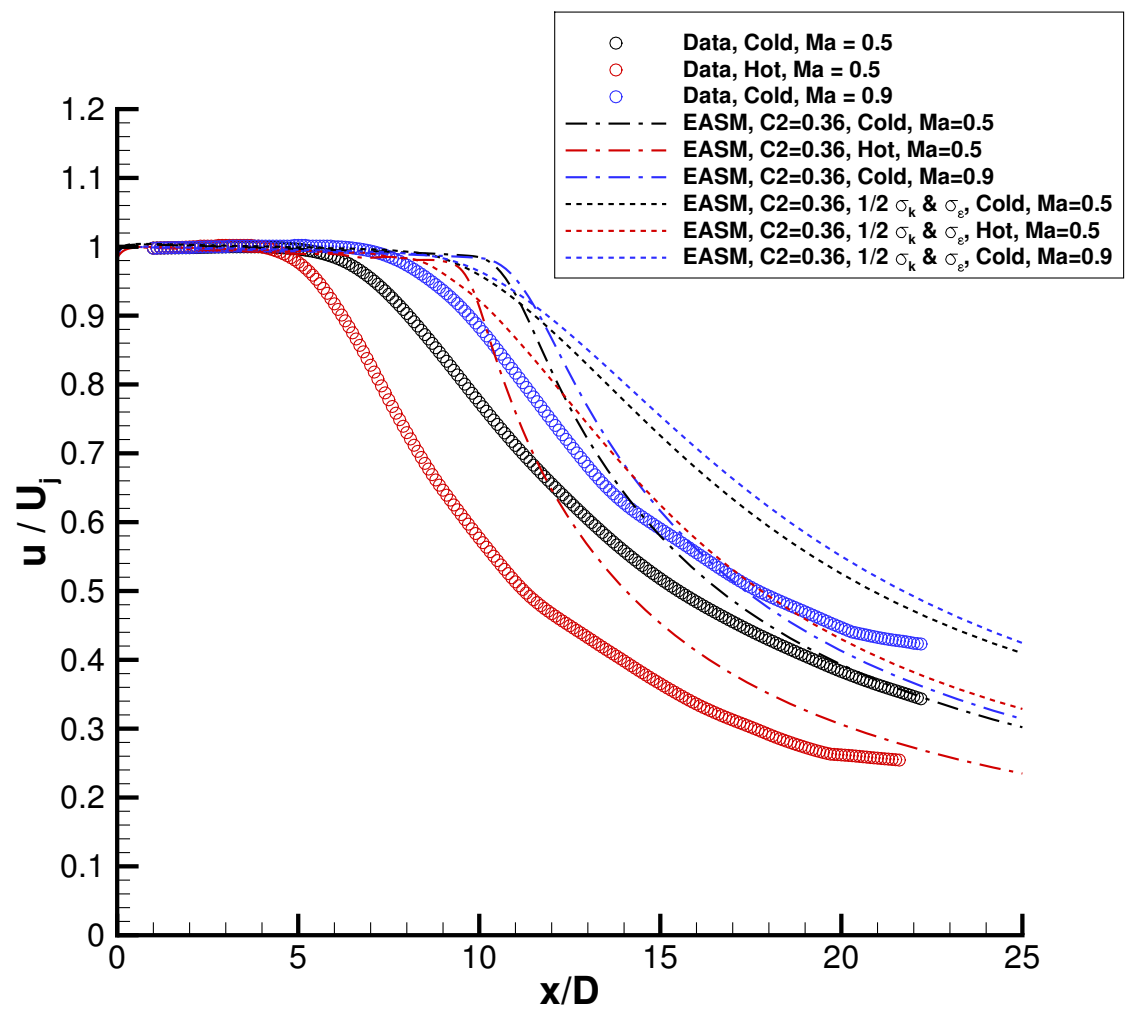

(a) Centerline velocity

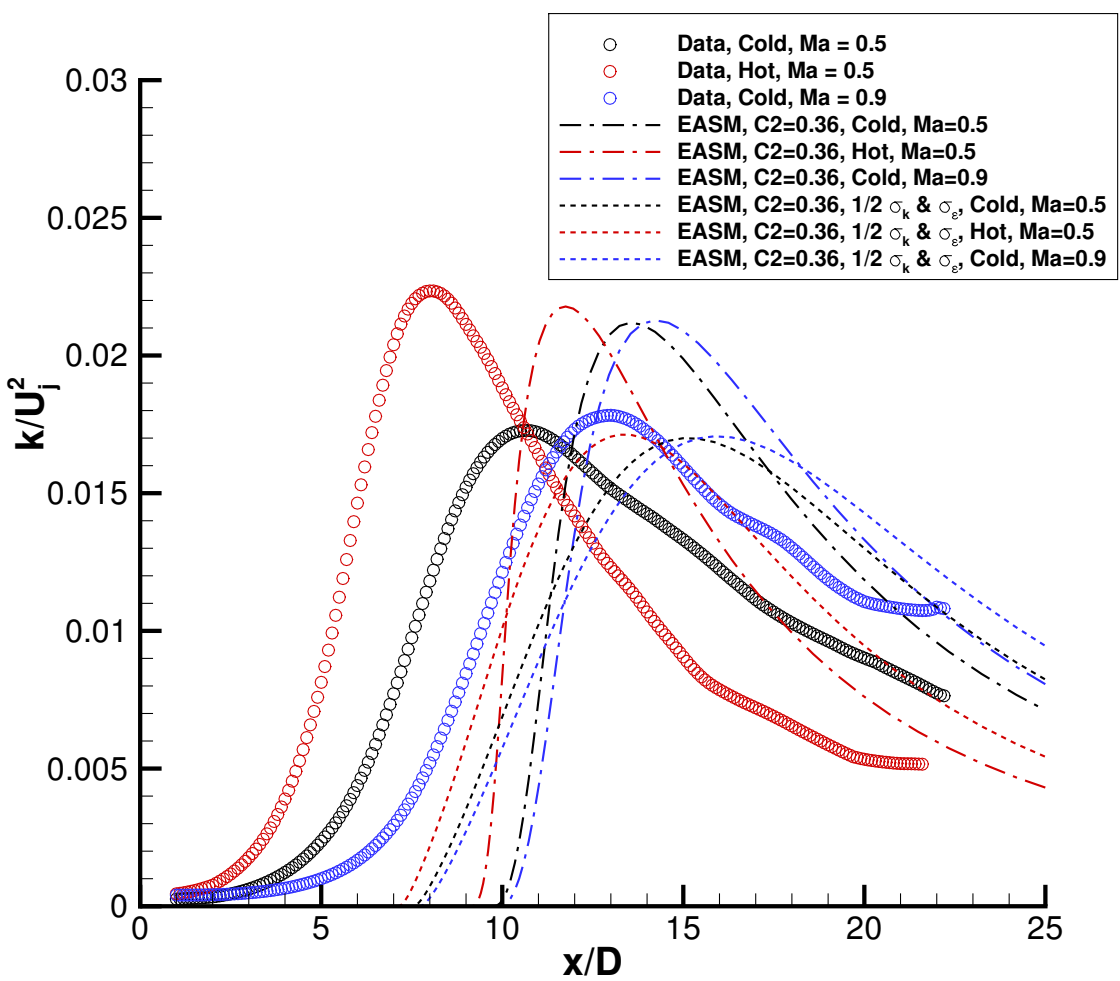

(b) Centerline turbulent kinetic energy

Figure 2. Comparison of modified EASM when varying $\sigma_{k}$ and $\sigma_{\epsilon}$ with standard value for $C_{2}=0.36$. 


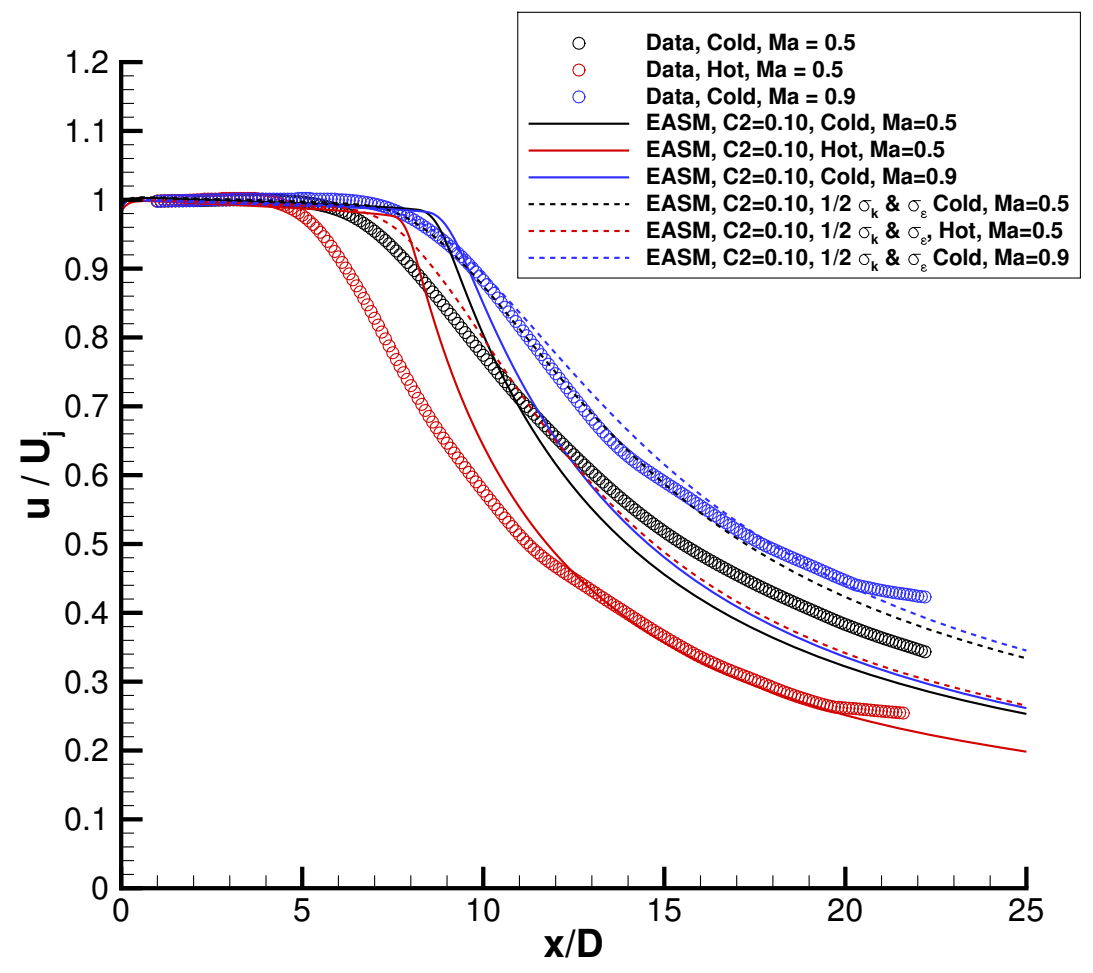

(a) Centerline velocity

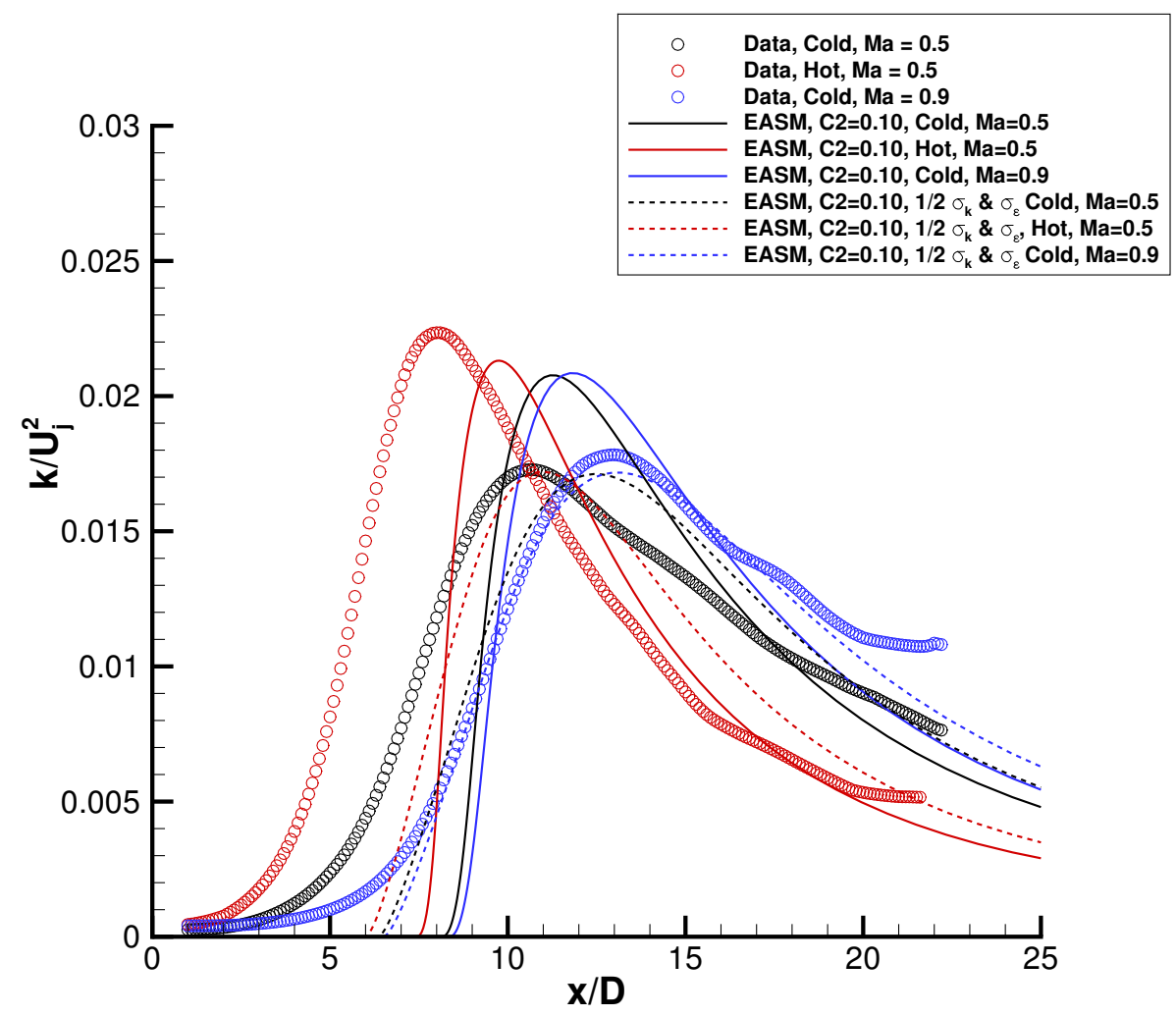

(b) Centerline turbulent kinetic energy

Figure 3. Comparison of modified EASM when varying $\sigma_{k}$ and $\sigma_{\epsilon}$ with $C_{2}$ lowered to 0.10. 


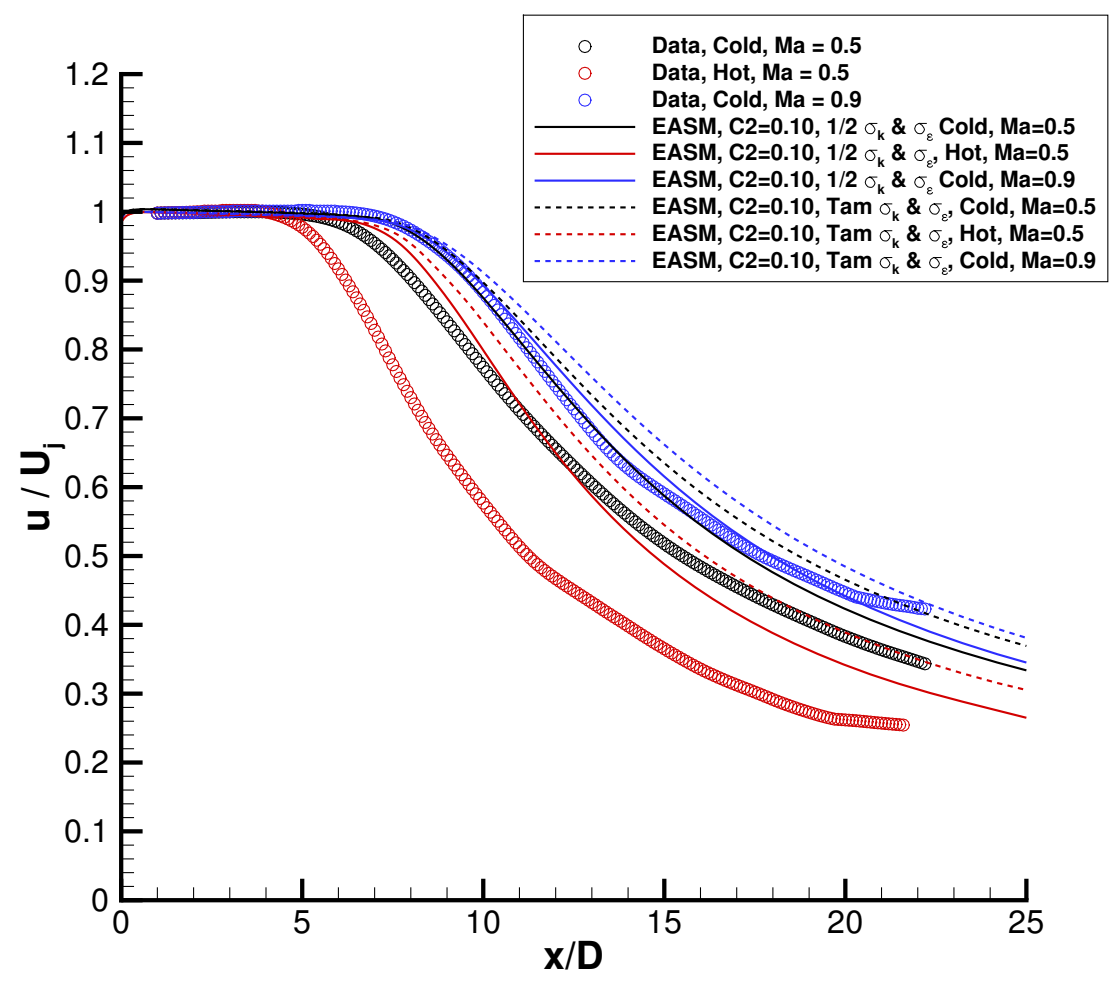

(a) Centerline velocity

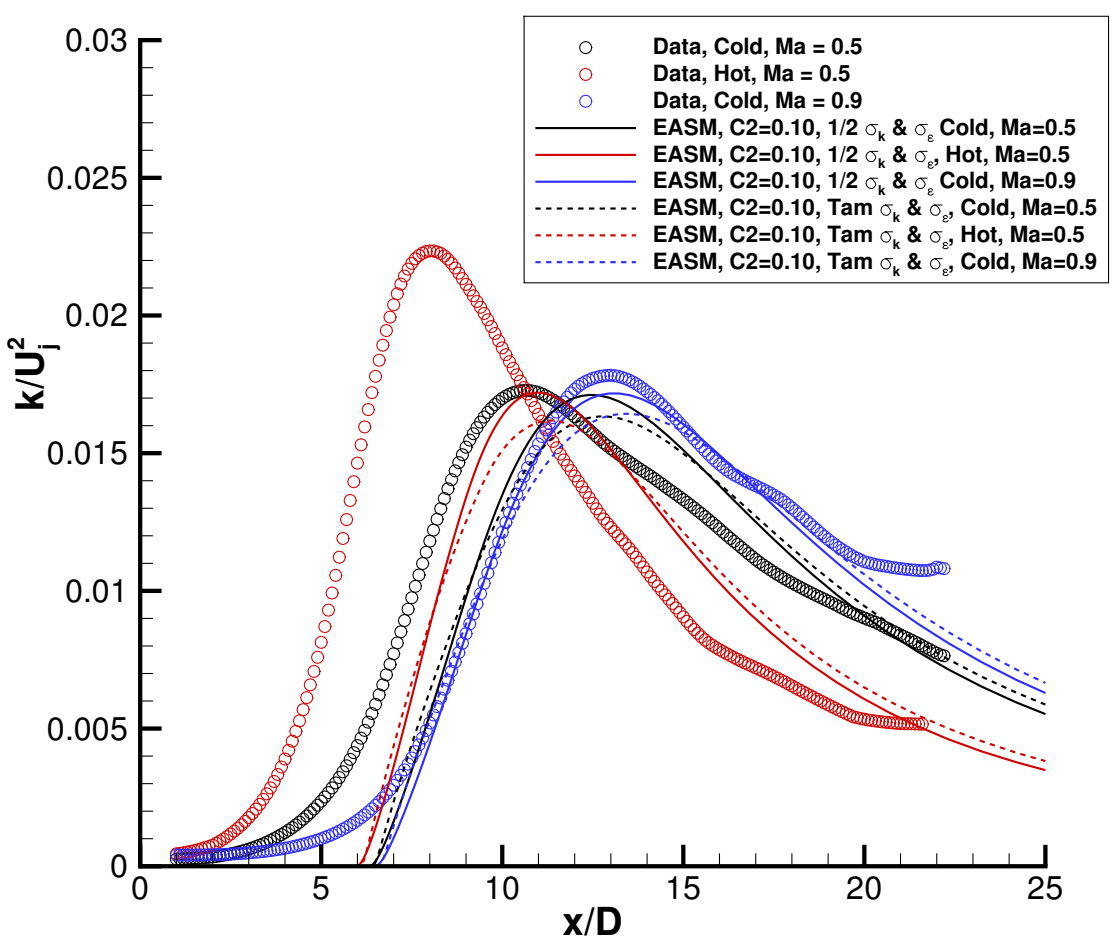

(b) Centerline turbulent kinetic energy

Figure 4. Comparison of modified EASM with reduced diffusion coefficients $\sigma_{k}$ and $\sigma_{\epsilon} ; C_{2}$ lowered to 0.10 . 


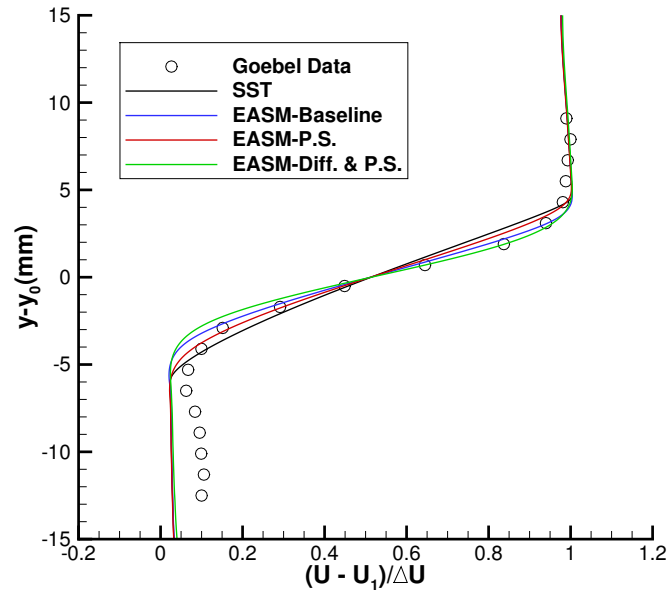

(a) $\mathrm{X}=150 \mathrm{~mm}$

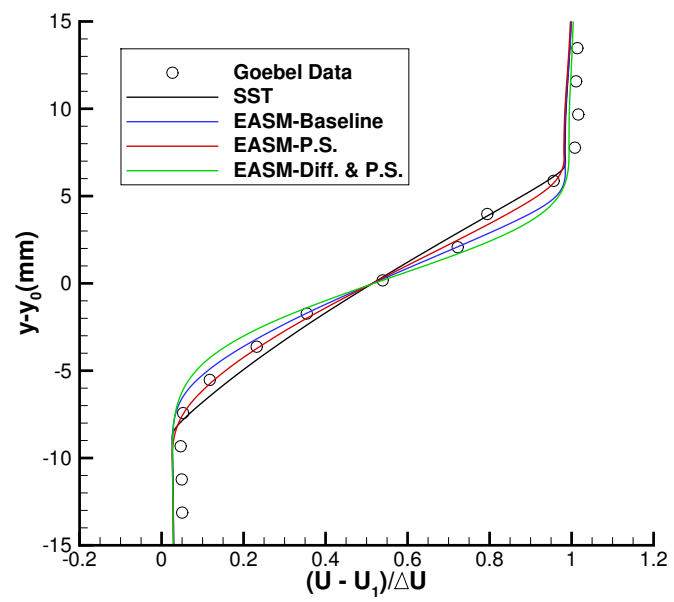

(b) $\mathrm{X}=250 \mathrm{~mm}$

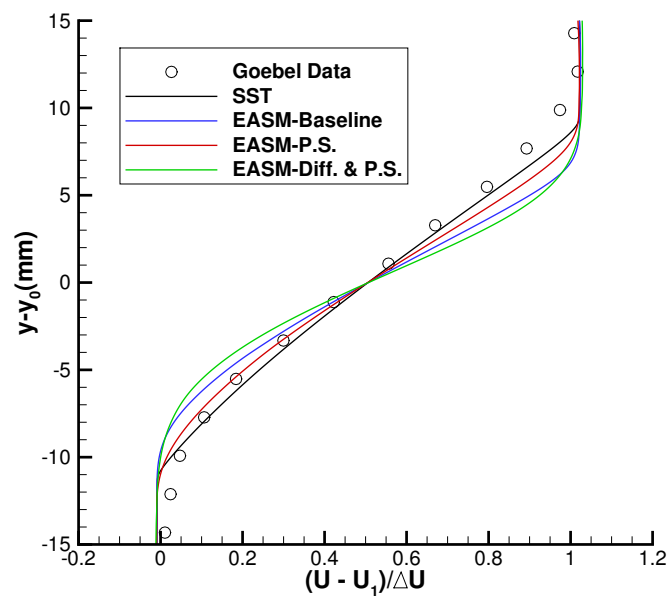

(c) $\mathrm{X}=350 \mathrm{~mm}$

Figure 5. Axial velocity profiles for Goebel-Dutton Mixing Layer.

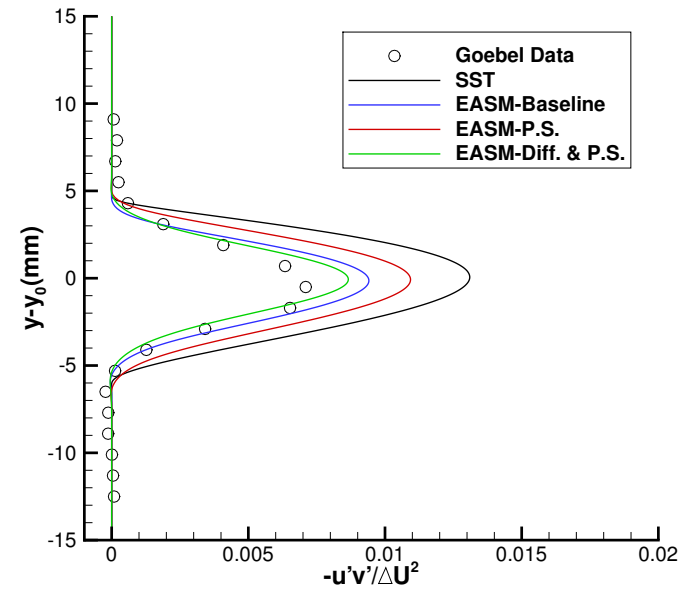

(a) $\mathrm{X}=150 \mathrm{~mm}$

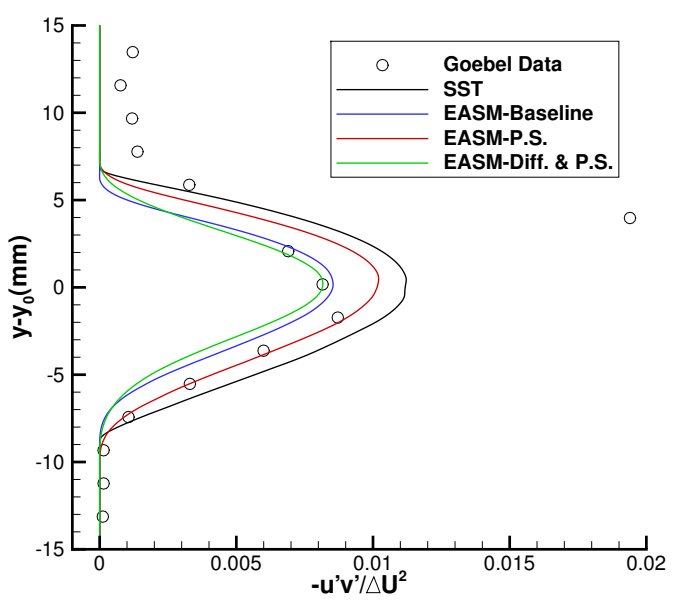

(b) $\mathrm{X}=250 \mathrm{~mm}$

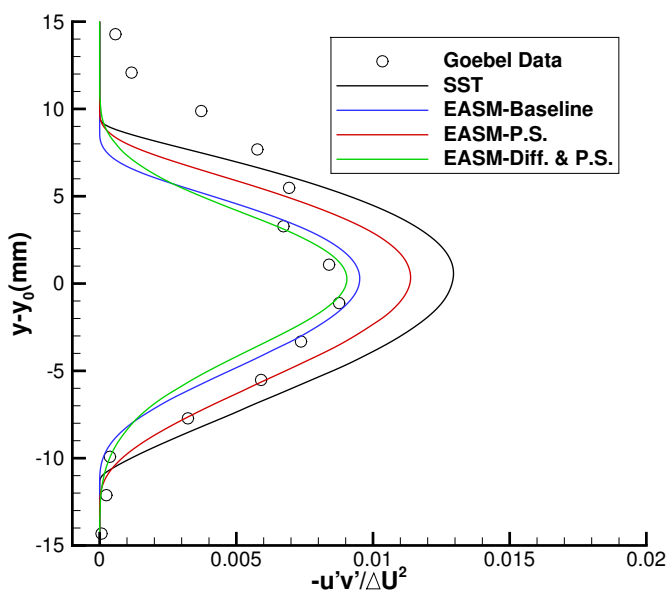

(c) $\mathrm{X}=350 \mathrm{~mm}$

Figure 6. Turbulent Shear Stress $(-u v)$ profiles for Goebel-Dutton Mixing Layer. 


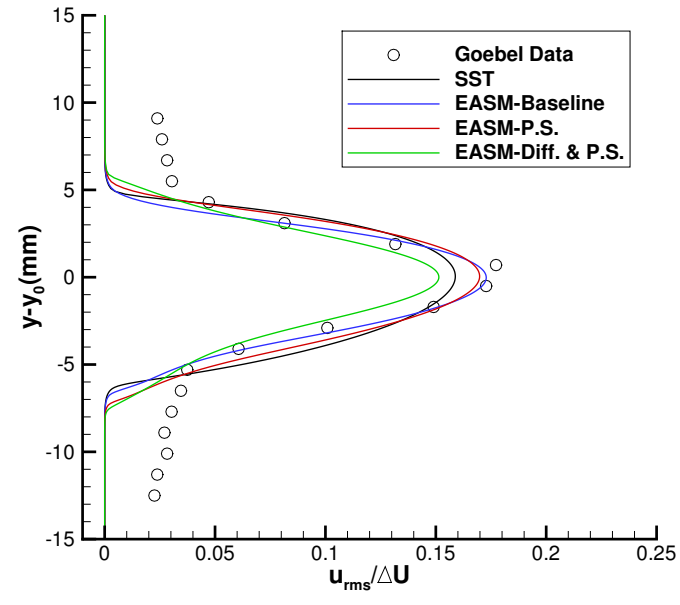

(a) $\mathrm{X}=150 \mathrm{~mm}$

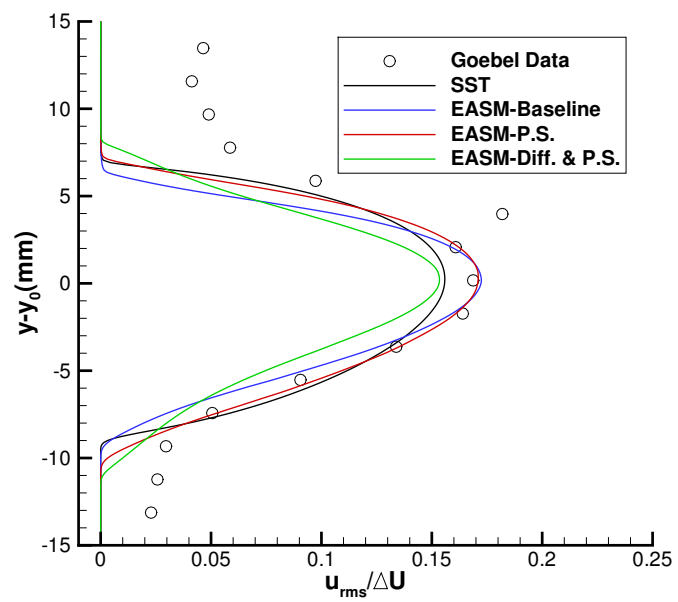

(b) $\mathrm{X}=250 \mathrm{~mm}$

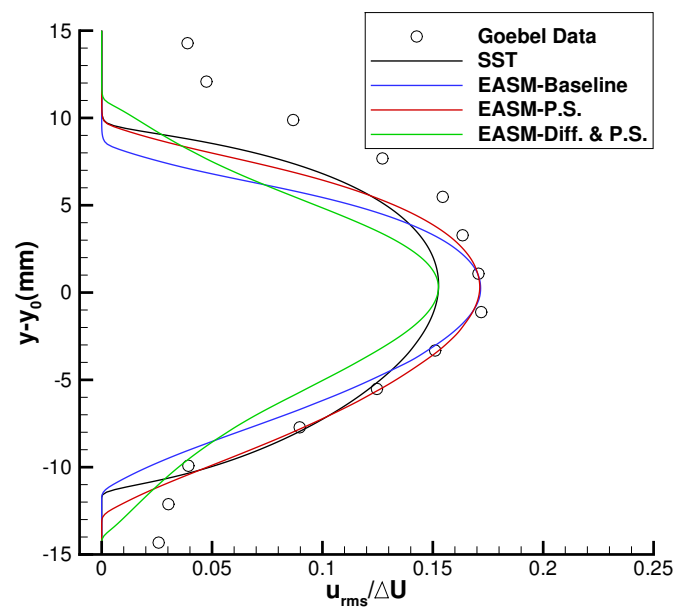

(c) $\mathrm{X}=350 \mathrm{~mm}$

Figure 7. $U_{r m s}$ profiles for Goebel-Dutton Mixing Layer.

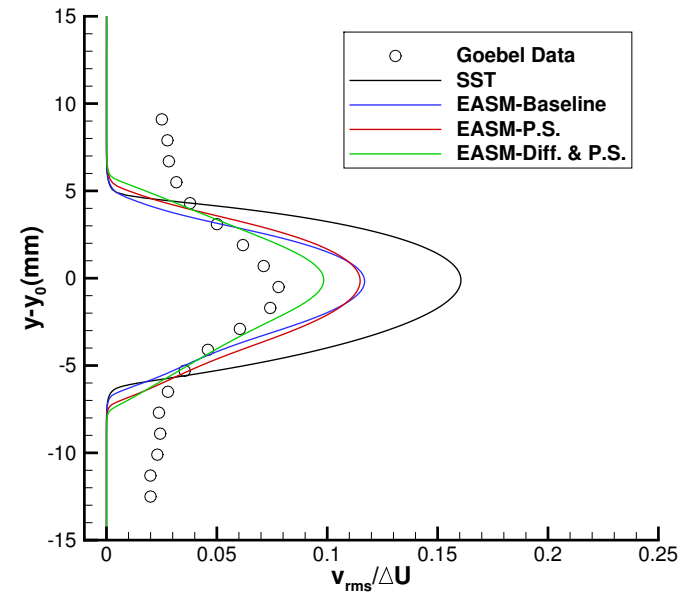

(a) $\mathrm{X}=150 \mathrm{~mm}$

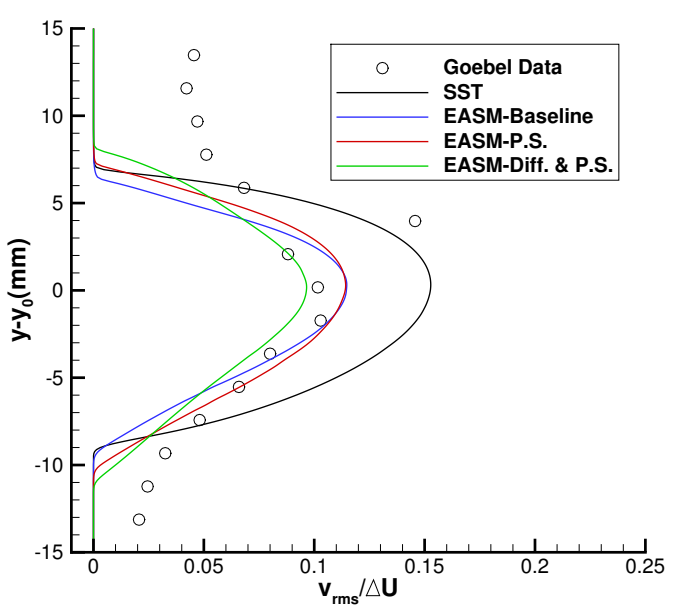

(b) $\mathrm{X}=250 \mathrm{~mm}$

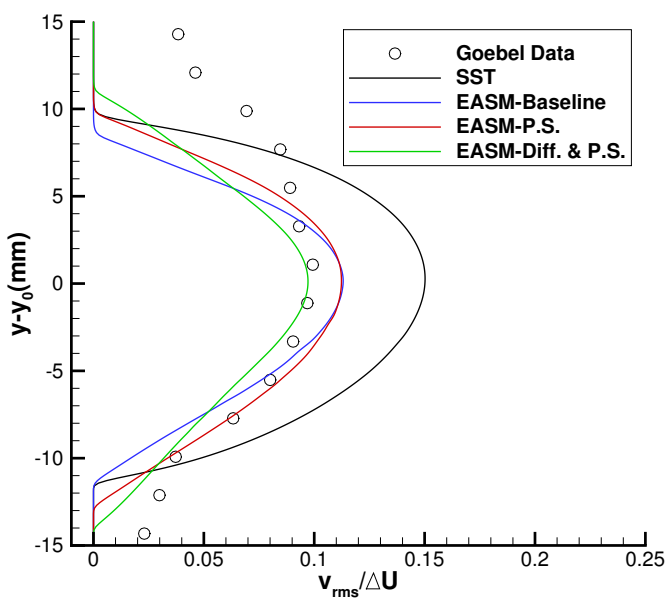

(c) $\mathrm{X}=350 \mathrm{~mm}$ 


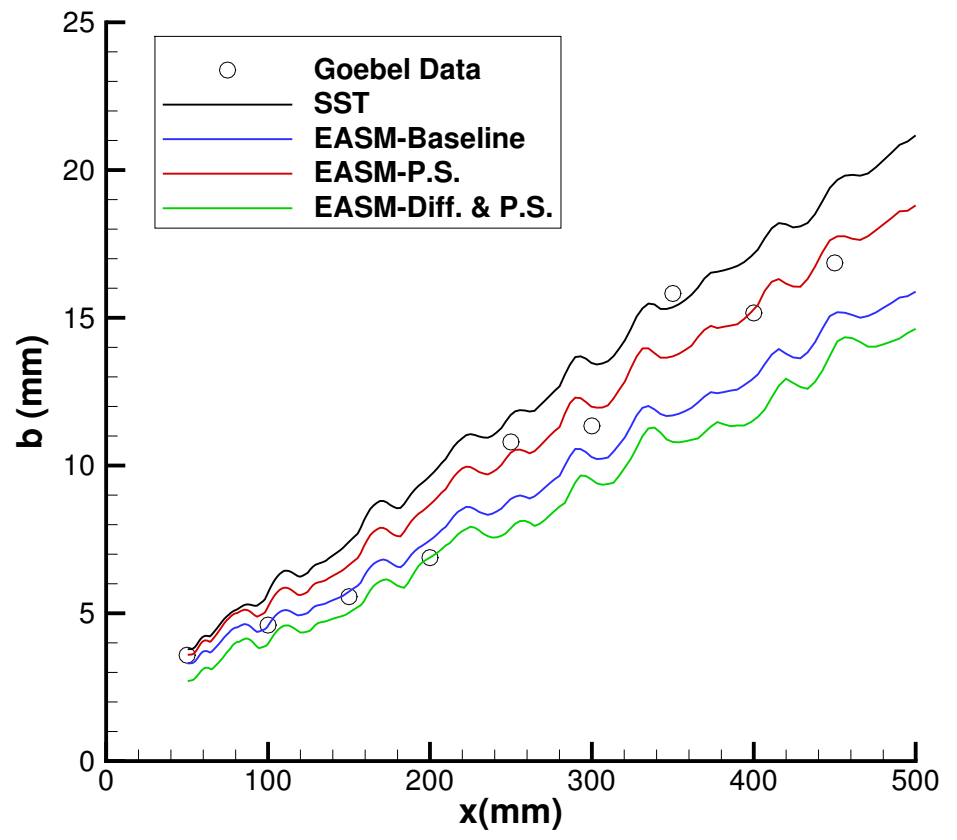

Figure 9. Mixing layer thickness. 


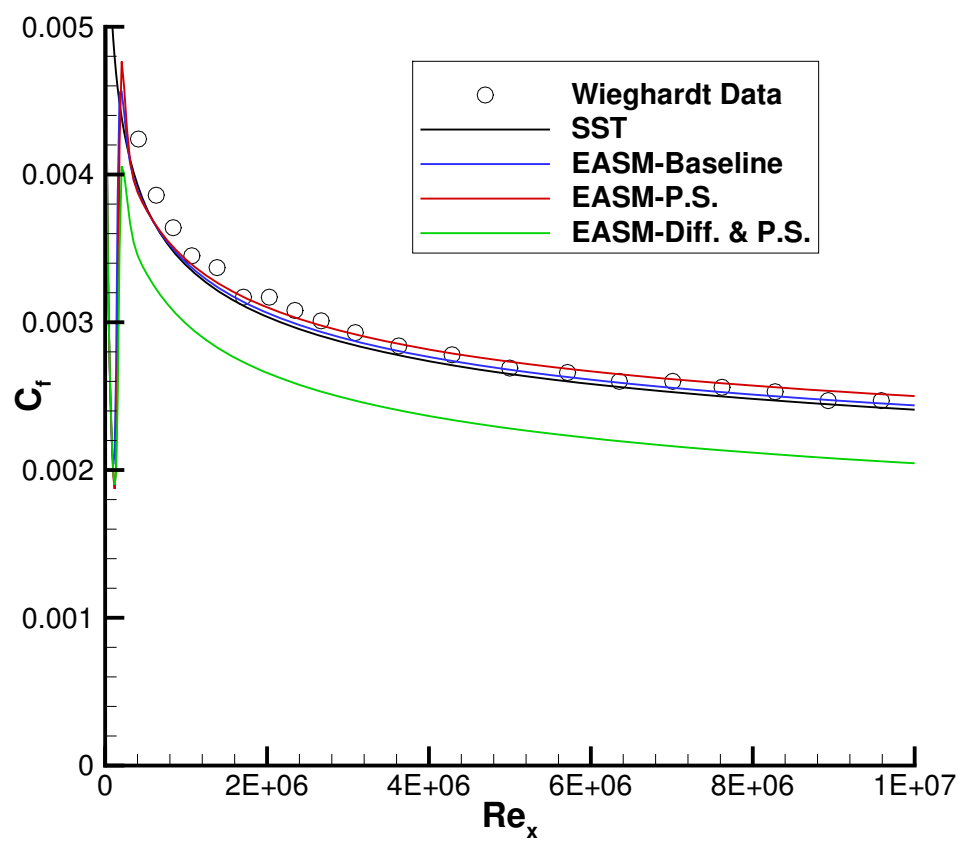

Figure 10. Skin friction for incompressible flat plate case. 


